\title{
Characteristics of Soil and Water Loss in Typical Bamboo Forest
}

\author{
Zhao-Wei Shen ${ }^{1 a}$, Sui-Gao Ye ${ }^{1 a}$, Li Gang ${ }^{2 a}$ \\ 'Zhejiang Key Laboratory of Water Conservancy Disaster Prevention and Reduction, Zhejiang \\ Institute of Hydraulics \& Estuary ,Hangzhou ,310020,China \\ 2Zhejiang Guang Chuan Engineering Consulting Co., Ltd. ,Hangzhou ,310020,China \\ a656375320@qq.com
}

\begin{abstract}
Key words: rainfall; runoff coefficient; soil and water loss; nutrient loss;
Abstract. the selection of pure bamboo forest, bamboo forest, bamboo Tong Yang Yang Tong Hemerocallis mixed forest as the research object, on the surface rainfall and 3 kinds of stand in the runoff, soil loss and nutrient loss (total nitrogen and total phosphorus) were studied. The results show that:. (1) the runoff coefficient is relatively high, followed by heavy rain. 3 stands in pure bamboo forest runoff coefficient is the largest, bamboo - Yang Tong - Hemerocallis mixed forest minimum. (2) the runoff coefficient, soil loss and nutrient loss of 3 kinds of stand were basically the same, all of which showed a trend of fluctuation. (3) the regression equation of rainfall and surface runoff and the regression equation of surface runoff and soil loss were all linear regression equations, which showed that the linear relationship between rainfall and surface runoff, surface runoff and soil loss.
\end{abstract}

\section{Introduction}

Bamboo is an important forest resources in South China, Zhejiang is one of the most abundant bamboo distribution in ${ }^{[1]}$ province. Zhejiang Province, a large quantity of bamboo resources, wide distribution, according to the announcement of the value of forest resources in Zhejiang province and its ecological function, 20 counties in the Mao Zhulin area of more than 10 thousand $\mathrm{Hm}^{2}$, and Anji County in the bamboo forest area is the largest, the most amount of bamboo ${ }^{[2]}$. Anji County, the total area of the county's total forest area of bamboo forest $37.8 \%{ }^{[3]}$. Since the beginning of 1990 s, the county bamboo farmers into the scale of the bamboo forest land reclamation, improve the quantity of bamboo and bamboo shoots out, significantly increased economic benefits, but also with the development of industrial economy, bamboo forest reclamation deeper and deeper, the area gradually expanded, a series of ecological environment problems gradually appear, such as: a large area bamboo forest was transformed into pure bamboo forest, resulting in loss of species, biodiversity, ecological poverty, poor stability; high strength and extensive management, resulting in most of steep mountains and serious soil erosion, water conservation function decline ${ }^{[4-6]}$.

Rainfall is one of the important factors that cause soil and water loss. The characteristics of rainfall intensity and rainfall intensity have important influence on the surface runoff and sediment ${ }^{[7-8]}$. In addition, the rainfall intensity and the degree of soil loss and occurrence frequency and so on are closely related ${ }^{[9-11]}$. The study of the relationship between rainfall and soil erosion is one of the important contents of soil and water conservation science, and it can provide scientific basis for the development of soil and water conservation project. Therefore, this research chooses Anji County of pure bamboo forest, bamboo forest and bamboo Tong Yang Yang Tong - Hemerocallis mixed forest as the research object, 6-10 statistics in 2015 monthly rainfall event analysis, rainfall intensity, runoff, soil loss and nutrient loss and the relationship between rainfall and the latter, to explore the 3 types of forest the characteristics of soil erosion, forest type configuration and provide a scientific basis for soil erosion control.

\section{General Situation of Study Area}

Anji county is located in the northwest of Zhejiang, the total area is about $1886 \mathrm{~km} 2$, which belongs to the typical subtropical marine monsoon climate, four seasons, the average annual precipitation is 
about $1550 \mathrm{~mm}$, uneven rainfall distribution in the year 4 and May for the spring season, the annual rainfall accounted for about 20\%; in June 5, Mei Yu Mingxian, accounting for annual rainfall 15\%; 7-9 months for typhoons, thunderstorms, rain season, many local thunderstorms. Years average temperature is 15.5 . Anji county forest coverage rate and vegetation coverage rate reached $71 \%$ and $75 \%$ respectively, mainly in the main vegetation types of vegetation. The soil is a hilly red soil, the soil layer is mainly medium and thick layer, the alluvial soil layer is thick, the soil is loose, and the soil is mainly soil, but the content of the soil is high ${ }^{[12]}$.

\section{Research Method}

In the study area is set 3 vegetation configuration mode, respectively, of pure bamboo forest, bamboo forest, bamboo Tong Yang Yang Tong - Hemerocallis mixed forest, each vegetation configuration mode was repeated 2 times, that is a total of 9 residential runoff layout. The rainfall collection device was measured using a simple artificial rainfall level measuring device is installed in the open space, built-in water storage equipment, indoor with rain gauge. When rainfall occurs, the rainfall record time (date), rain water storage device and water storage, when rainfall at the end (about $1 \mathrm{H}$ rain), record the stop of rainfall time, and remove the water equipment, water consumption amount of cylinder volume record. Determination of runoff and sediment yield by measuring the depth of water in the pool when rainfall exceeds $20 \mathrm{~mm}$. If the water is clear, but not otherwise sampling; sampling time for cleaning tank. Determination of total nitrogen by alkaline potassium sulfate ultraviolet spectrophotometry (11894-89 GB), total phosphorus determination using vanadium molybdenum phosphoric acid colorimetric method. Data analysis using SPSS 19 and Excel analysis.

\section{Rainfall Characteristics}

As shown in Figure 1, statistical analysis of Anji County 6-10 month a total of 25 rainfall events, rainfall and rainfall intensity features are as follows: Anji County rainfall 6-10 month showed a trend of fluctuations, the minimum rainfall is $6.0 \mathrm{~mm}$, the maximum rainfall is $106.0 \mathrm{~mm}$, rainfall mainly concentrated in the $30 \mathrm{~mm}$. The intensity of rainfall is the same as that of rainfall, which is obviously fluctuating, but the fluctuation pattern is slightly different from that of rainfall, which is related to the duration of rainfall. According to figure 1, the rainfall intensity between $0.18-5.67 \mathrm{~mm} / \mathrm{h}$. According to the rainfall intensity grade will be divided into: light rain rainfall intensity $(<0.42 \mathrm{~mm} / \mathrm{h})$, moderate $(0.42 \mathrm{~mm} / \mathrm{h}=<1.25 \mathrm{~mm} / \mathrm{h}$, heavy rain (rain) heavy rain and storm $1.25 \mathrm{~mm} / \mathrm{h}=\langle 2.5 \mathrm{~mm} / \mathrm{h})([13]=2.5 \mathrm{~mm} / \mathrm{h})$. Therefore, to divide the Anji County 25 rainfall intensity, rain that accounted for $4 \%$, moderate rain accounted for $36 \%$, accounted for $40 \%$, accounting for $20 \%$ of the rainfall, rainfall is moderate rain and heavy rain.

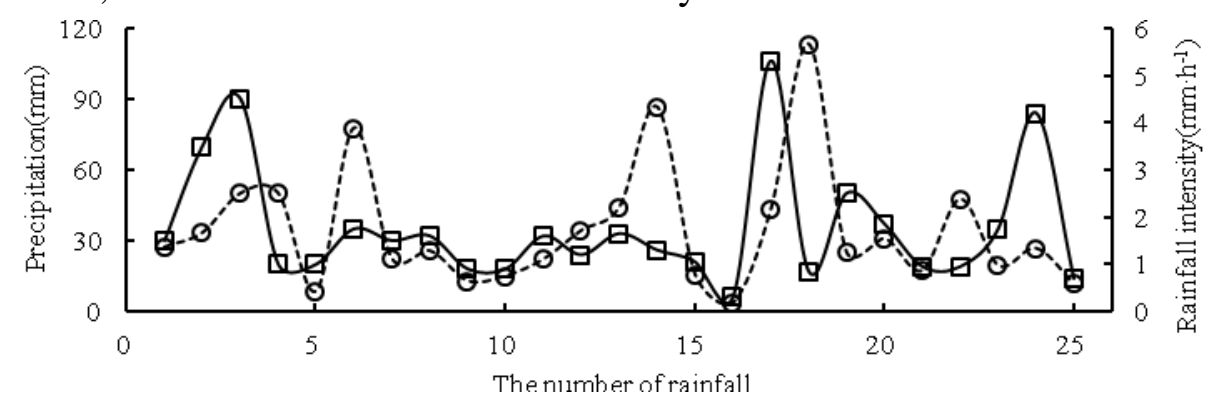

Fig. 1 the distribution of rainfall intensity and rainfall intensity

\section{Soil and Water Loss in Mao Zhulin Composite Operation}

In Anji County of pure bamboo forest, bamboo mixed forest and bamboo Tong Yang Yang Tong Hemerocallis mixed forest 3 forest types in 6-10 months a total of 11 times of soil erosion 
monitoring and analysis of the situation, the acquisition of 1 field rain, rain storm 5 and 5 in the context of runoff, soil loss, total nitrogen the amount of nutrient loss and total phosphorus nutrient loss, the results are shown in table 1 . It can be seen from table 1, the corresponding rainfall runoff coefficient is relatively high, followed by heavy rain, the rain. It shows that the rainfall intensity is bigger, the runoff coefficient is bigger, the runoff is more easy to produce, and the smaller the runoff coefficient is. Therefore, heavy rainfall is the main driving force of soil erosion ${ }^{[14]} .3$ stands in pure bamboo forest runoff coefficient is the largest, Yang Tong bamboo mixed forest, bamboo Yang Tong - Hemerocallis mixed forest is minimum, that plant species diversity is more conducive to retain the rainfall, and the pure bamboo forest structure is simple, easy to produce runoff, which makes the relative maximum runoff coefficient.

Table 1 statistic of soil loss in bamboo forest in different configuration mode

\begin{tabular}{|c|c|c|c|c|c|c|c|}
\hline \multirow{2}{*}{$\begin{array}{l}\text { Rainfall } \\
\text { leve }\end{array}$} & \multirow[b]{2}{*}{ rainfall $(\mathrm{mm})$} & \multicolumn{3}{|c|}{ Runoff coefficient $(\%)$} & \multicolumn{3}{|c|}{ Soil loss（kg/ha） } \\
\hline & & Pure bamboo & $\begin{array}{c}\text { Bamboo } \\
\text { - Yang Tong }\end{array}$ & $\begin{array}{c}\text { Bamboo } \\
\text { - Yang Tong - Lily }\end{array}$ & Pure bamboo & $\begin{array}{c}\text { Bamboo } \\
\text { - Yang Tong }\end{array}$ & $\begin{array}{c}\text { Bamboo } \\
\text { - Yang Tong - Lily }\end{array}$ \\
\hline Moderate & 30.0 & 1.18 & 1.02 & 1.05 & 9.67 & 10.00 & 7.00 \\
\hline Heavy & 30.0 & 6.30 & 5.38 & 6.00 & 83.78 & 61.15 & 70.00 \\
\hline Heavy & 70.0 & 10.00 & 6.00 & 8.00 & 270.00 & 196.00 & 119.00 \\
\hline Heavy & 14.0 & 4.42 & 3.00 & 2.43 & 19.59 & 20.00 & 10.84 \\
\hline Heavy & 24.0 & 5.71 & 5.00 & 2.76 & 55.00 & 32.00 & 20.30 \\
\hline Heavy & 106.0 & 0.95 & 1.10 & 0.78 & 9.92 & 6.50 & 8.00 \\
\hline Rainstorm & 17.0 & 1.15 & 1.11 & 0.73 & 9.60 & 10.00 & 5.66 \\
\hline Rainstorm & 37.0 & 6.29 & 5.66 & 5.03 & 134.00 & 99.00 & 30.00 \\
\hline Rainstorm & 90.0 & 4.12 & 5.00 & 3.00 & 15.76 & 16.00 & 12.00 \\
\hline Rainstorm & 20.0 & 5.59 & 4.08 & 3.60 & 49.52 & 54.00 & 20.00 \\
\hline Rainstorm & 35.0 & 1.79 & 1.67 & 1.19 & 4.95 & 5.00 & 2.65 \\
\hline
\end{tabular}

\section{Surface Runoff}

The surface runoff dynamics of 3 kinds of forest stands were analyzed, and the results are shown in Figure 2. From Figure 2, we can know that the 3 types of runoff coefficient change trend is basically the same, there was a significant fluctuation trend, the maximum value appeared in June 19th, reaching $10 \%$, corresponding to heavy rain, the minimum value appeared in July 13th, only $0.7 \%$. June and August runoff coefficient is relatively large, in the collection of 11 rain, 5 heavy rain in June and August, and 5 of the 3 heavy rain in 4 fields are concentrated in more than two months. So the runoff coefficient in June and August is relatively large compared to the other two months. In addition, pure bamboo forest runoff coefficient is always greater than the other two stands.

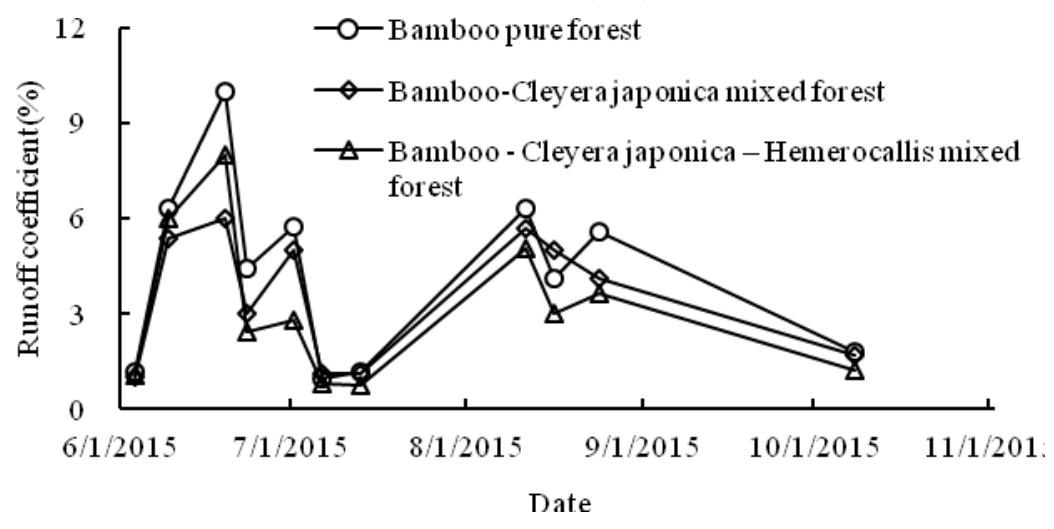

Fig. 2 Variation of runoff coefficient

\section{Soil Loss}

For 6-10 months 3 forest soil loss analysis, the variation trends consistent with soil erosion, soil erosion but bamboo pure forest was always greater than the other two stands (Figure 3). In combination with figure 2, it can be seen that the greater the runoff, the greater the loss of soil loss in 3 kinds of forest stands, and the difference of soil loss between different stand. Soil loss in June 
reached the maximum, reaching $270 \mathrm{~kg} / \mathrm{ha}$, the smallest in October, only $2.7 \mathrm{~kg} / \mathrm{ha}$. Rainfall intensity is one of the main causes of soil loss, the greater the rain, the rain is too concentrated, the greater the impact on the soil surface. Due to heavy rain and heavy rain mainly concentrated in June and August, so a large number of soil loss is mainly concentrated in June and August.

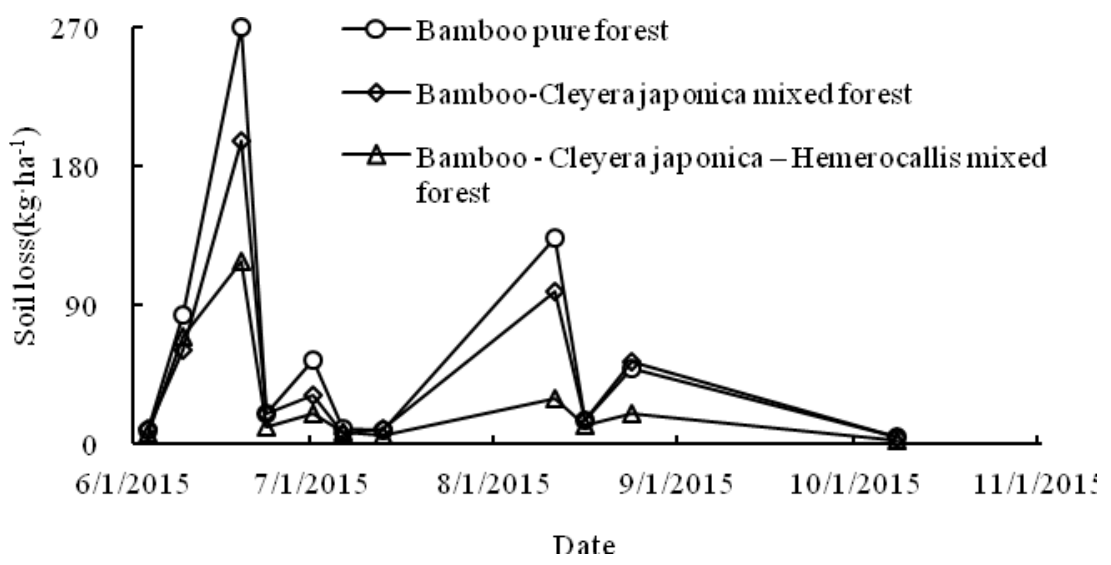

Fig. 3 changes of soil loss

\section{Relationship between Rainfall and Soil Erosion}

Application of Pearson on rainfall, runoff coefficient, soil loss for SPSS correlation analysis, found that there was a correlation between the various factors, R2 in $0.650-0.995$.

The regression equation of rainfall and surface runoff and the regression equation of surface runoff and soil loss were all linear regression equations, which showed that the linear relationship between rainfall and surface runoff, surface runoff and soil loss (Table 2). Among them, the runoff with the rainfall increases, this is due to the surface by raindrops blow to form muddy mud, mud, soil pore blockage in the infiltration process, resulting in reduced infiltration of rainwater, which makes the rapid increase of surface runoff, rainfall is usually more easy to form surface runoff ${ }^{[15]}$. The soil loss increased with the increase of runoff. Rainfall induced soil erosion by surface runoff. Rainfall will surface soil peeling, the formation of rain splash erosion, runoff is responsible for the stripping of soil particles migration and take away. Therefore, soil loss increased with the increase of runoff.

Table 2 Relationship Model of surface runoff and soil loss

\begin{tabular}{ccc}
\hline Sample type & regression equation & $R^{2}$ \\
\hline Pure bamboo & $\mathrm{y}=0.066 \mathrm{x}+0.021$ & 0.872 \\
Bamboo - Yang Tong & $\mathrm{y}=0.043 \mathrm{x}+0.016$ & 0.703 \\
Bamboo- Yang Tong - Lily & $\mathrm{y}=0.062 \mathrm{x}+0.014$ & 0.919 \\
\hline
\end{tabular}

\section{Conclusion}

(1) the monthly rainfall of 6-10 in Anji county showed a trend of obvious fluctuation, and the amount of rainfall was $6.0-106.0 \mathrm{~mm}$. According to the rainfall intensity grade 25 rainfall in Anji county is divided into light rain, moderate rain and heavy rain. The light rain, moderate rain accounted for $4 \%$, accounted for $36 \%$, accounted for $40 \%$ of the heavy rain, heavy rainfall accounted for $20 \%$, mainly for moderate rain and heavy rain.

(2) the Anji rainstorm runoff coefficient corresponding to the relatively high, followed by heavy rain, the rain. 3 stands in pure bamboo forest runoff coefficient is the largest, bamboo - Yang Tong Hemerocallis mixed forest minimum. And the trend of runoff coefficient, soil loss and nutrient loss were basically the same, which showed a trend of fluctuation. In June and August, the runoff coefficient, soil loss and nutrient loss were relatively large.

(3) the regression equation of rainfall and surface runoff and the regression equation of surface runoff and soil loss were all linear regression equations, which showed that the linear relationship between rainfall and surface runoff, surface runoff and soil loss. 


\section{Acknowledgements}

This work was financially supported by Natural Science Foundation of Zhejiang Province of china(Grant No. LY14E090005), Department of Science and Technology of Zhejiang Province(Grant No. 2014F50015).

\section{Reference}

[1] Ann Yanfei. Zhejiang important bamboo's underground system structure and biomechanical study of [D]. Chinese Forestry Research Institute, 2009

[2] Pan Chunxia, Li Xuetao, Lv Yulong. Study on bamboo resources in Anji county and its biomass [J]. Zhejiang forestry science and technology, 2010, 30 (1): 82-84.

[3] Xu Xiaojun. Estimation of carbon storage in the upper part of Mao bamboo forest based on TM [D]. image LANDSAT Zhejiang Forestry University, 2009

[4] Liu Ying, Luo Raymond Lam. Design and application of soil and water loss control measures for bamboo forest [J]. China soil and water conservation, 2015 (11): 26-27.

[5] Wang Yingxiang, Zhang Jinchi, Liu Xin, et al. Response of soil moisture to soil moisture on soil moisture in the hilly area of South of Jiangsu hilly region [J]. Bulletin of soil and water conservation, 2016, 36 (1): 22-26.

[6] Li Guohua. Characteristics of soil and water loss in bamboo forest and its prevention and control [J]. sub tropical soil and water conservation, 2008, 20 (3): 57-58.

[7] Bi H X, Liu B, Wu J, et al.Effects of precipitation and Landuse on runoff during the past in a typical watershed 50 years in the loss plateau, China [J]. International Journal of Sediment Research, 2009, 24 (3): 352-364.

[8] Li Guang, Huang Gaobao. Effects of rainfall intensity and land use on Soil and water loss in Loess Hilly Region [J]. Journal of agricultural engineering, 2009, 25 (11): 85-90.

[9] Fang N F Shi Z H Li L et al. The effects of rainfall regimes and land use changes on runoff and soil loss in a small mountainous watershed [J]. Catena 2012 (99): 1-8.

[10] Wei W, Chen L D, Fu B J, et al. The effect of land uses and rainfall regimes on runoff and soil erosion in the semi-arid loess hilly area, China [J]. Journal of Hydrology, 2007, 335 (3-4): 247-258.

[11] Yan Qinghong, Yuan Cuiping, Lei Tingwu, et al. Types of rainfall and soil and water conservation effect of soil erosion of small watershed in loess area [J]. Journal of agricultural machinery, 2014, 45 (2): 169-175.

[12] in the establishment of a Chinese type of ecological development model: Anji research. Urban development research, 2009, 16 (10): 86-91

[13] Peng Chi. Study on plant selection and ecological effects of compound forest of bamboo and bamboo forest [D]. Zhejiang agriculture and Forestry University, 2012, 19-20.

[14] Li Li. Soil properties and soil and water loss characteristics of Eucalyptus Plantations in southern Guangxi, Guangxi University,, 2014, 26-27.

[15] Jiang Miaohua, Huang Rongzhen, Xie Jinsheng, et al. Study on the effect of different rainfall intensity on Soil and water loss of bare sloping land [J]. Journal of Subtropical Resources and environment, 2011, 06 (4): 24-28. 